\title{
Investigating the Effectiveness of Comparative Advertising: The Roles of Structural Alignability and Message Informativeness
}

\author{
Tommy Hsu \\ Tarleton State University
}

In the marketing literature, there are inconclusive findings about the effectiveness of comparative advertising. The mixed results from previous studies would certainly lead us intuitively to believe in the possibility of the existence of moderating or mediating variables. This research aims for contributing to the extant literature by investigating the moderating effects of structural alignability and the mediating effects of message informativeness. To our best knowledge, no previous published research has specifically focused on how these two variables influence comparative ads. An experimental study was conducted and the research findings are presented. The managerial implications, limitations, and future research recommendations are also discussed.

Keywords: comparative advertising, structural alignability, informativeness, advertising message

\section{INTRODUCTION}

In comparative advertising, one of the most common ways that companies make comparison arguments is to claim that they have some "special attributes" that their competitors lack instead of comparing similar attributes. This structural alignability of the attributes requires consumers to process the information in a different way (Chang 2007). Structural alignability has been studied for decades, but very little has been done in the comparative advertising context. To my best knowledge, there is no research that specifically addresses how the use of alignable differences influences the effectiveness of direct versus indirect comparative advertising. Structural alignability is an important factor in comparative advertising because research has shown that consumers exhibit greater difficulty in processing nonalignable versus alignable features (Zhang and Fitzsimons 1999; Zhang and Markman 2001; Chang 2007; Herrmann et al. 2009). Because of this difficulty, consumers may respond differently to comparative advertisements where alignable differences are utilized.

Structural alignability "refers to the ease with which the attributes of one object can be aligned or mapped onto another object" (Zhang 2002, p. 304), which means whether the compared attributes used in a comparative advertisement are perceived comparable by consumers. When consumers make comparisons, not only does the similarity between two objects matter but the differences between these two are also important. The comparisons indicate what information consumers should particularly pay attention to: the aligned structure and its associated alignable differences (Markman and Gentner 1997). When the focal attribute can be mapped into the compared attribute, it refers to an alignable difference (Markman and Gentner 1993; Gentner and Markman 1994; Zhang, Kardes, and Cronley 2002; Chang 2007). Comparative advertisements using alignable differences are most commonly used. For example, when a car company 
compares itself with its competitors in an advertisement in terms of tire stability, engine power or fuel efficiency, this advertisement is considered to be using alignable differences because the compared attributes can be found in both the advertiser's and the competitors' cars.

On the other hand, when the compared attribute is unique to the focal brand and cannot be found in compared brands' products, it refers to a nonalignable difference (Markman and Gentner 1993; Gentner and Markman 1994; Zhang et al. 2002; Chang 2007). For example, when the cell phone with the built-in camera was first introduced and was used to compare with other regular cell phones in an advertisement, this advertisement is considered to be using nonalignable differences because the built-in camera can only be found in the focal brand's product and is a unique feature of the focal brand.

Prior research has demonstrated that it is easier for consumers to compare alignable differences than non alignable differences (Zhang and Fitzsimons 1999; Chang 2007) because alignable differences provide consumers more comprehensive information and all objects or products in the advertisement have a comparable representation (Zhang and Fitzsimons 1999). Processing alignable differences requires less cognitive effort and is considered to be a less difficult job for consumers than processing nonalignable differences (Chang 2007). Therefore, alignable differences are found to be more effective in consumers' recalls (Markman and Gentner 1997), analogical reasoning, memory accessibility (Markman and Medin 1995), and decision-making processes than nonalignable differences (Zhang et al. 2002; Chang 2007; Herrmann et al. 2009). Most importantly, research has found that comparative advertising can increase target brand evaluation when it focuses on alignable differences (Zhang et al. 2002).

On the contrary, nonalignable differences are found to be more difficult for consumers to process and remember (Zhang and Fitzsimons 1999; Chang 2007). Consumers often find advertisement messages containing nonalignable differences of the attributes too complex. Therefore, those advertisements are less likely to be remembered (Markman and Medin 1995) and less effective in generating consumers' attentions and increasing target brand evaluations than those containing alignable differences (Zhang et al. 2002). Moreover, choosing among nonalignable options introduces the potential for regret because it requires trade-offs among features (Griffin and Broniarczyk 2010). However, companies commonly use comparative advertisements featuring nonalignable differences to differentiate, promote, and highlight their products, and consumers often do use nonalignable differences of different products to help them form preferences (Zhang and Markman 2001).

Although nonalignable differences increase consumers' cognitive load (Griffin and Broniarczyk 2010), direct comparative advertisements with nonalignable differences can be more effective since direct comparative advertising can motivate consumers to process the arguments in the advertisement message and make consumers who were exposed to direct comparative advertising perceive the advertisement to be more interesting and valuable (Pechmann and Esteban 1993). As Zhang et al. (2002) suggest, direct comparative advertising can potentially increase alignability by specifically naming the competing brand in the advertisement so that consumers may find it easier to compare two specific brands even though nonalignable differences are utilized. However, in indirect comparative advertising, different consumers may refer to different compared brands. Therefore, an indirect comparative advertisement using nonalignable differences may make the already-difficult job even more difficult for consumers. Consequently, it can be much less effective than direct ones with alignable differences.

On the other hand, since alignable differences receive more weight and generate more consumer attention than nonalignable differences (Zhang, Kardes et al. 2002), consumers should not have difficulty in processing the advertising messages regardless of whether it is direct or indirect comparative advertising. No matter if one specific brand or one (or more) unspecified brands is compared in the advertisement, information provided by alignable differences is comprehensive and comparable enough for consumers to process and make judgments. Therefore, no difference between the effectiveness of direct and indirect comparative advertisements is expected when alignable differences are utilized. Thus, the hypothesis for the moderator of structural alignability is as following.

Hypothesis: Structural alignability moderates the relationship between advertising directness and attitude towards the brand, such that, 
a) when the comparative advertisement features alignable differences, there is no difference in attitude towards the brand generated by direct and indirect comparative advertisements; and

b) when the comparative advertisement features nonalignable differences, direct comparative advertisements generate more positive attitude towards the brand than indirect comparative advertisements.

\section{THE STUDY}

This study aimed at investigating the moderator, structural alignability, as stated in the Hypothesis, and the mediator, message informativeness. In this study, tablet computers (Samsung vs. Apple) were used as the stimulus for the study.

\section{Design and Procedure}

152 American adults completed surveys with Amazon Mechanical Turk (mTurk). The sample consisted of $69(45.4 \%)$ male and $83(54.6 \%)$ female participants. Respondents' ages ranged from 18 to 67 years old with an average age of 35.4 years old and a standard deviation of 10.4. Respondents were mostly Caucasian Americans (76.3\%).

An experiment was conducted in which a 2 (advertising directness: direct/indirect comparative advertising) x 2 (structural alignability: alignable differences/nonalignable differences) between-subject design was used. Similar to Studies 1, advertising directness was manipulated by whether Samsung specifically named Apple (direct comparative advertising) or not (indirect comparative advertising) in the advertisement. On the other hand, structural alignability was manipulated by the wording Samsung used in the advertisement: "With the built-in solar charger, Samsung Galaxy Tab needs only 1 hour to be fully charged...Apple iPads/All other brands? 3+ hours!" (alignable differences) or "The newest Samsung Galaxy Tab offers the built-in solar charger...Apple iPads/All other brands? They don 't!" (nonalignable differences).

Participants were randomly assigned into one of the four experimental conditions (direct and alignable differences, direct and nonalignable differences, indirect and alignable differences, and indirect and nonalignable differences). First, each participant was shown the advertisement assigned and asked to read the advertisement carefully. After that, the participant was asked questions as manipulation checks. In the end, the participant was asked a series of questions regarding his/her attitude toward the focal brand, demographic information and whether he/she owned the product.

\section{Manipulation Check}

Similar to the manipulation checks in the previous study, participants were asked to respond by stating the degree to which they agreed or disagreed using a seven-point strongly disagree/agree scale with the following two questions: "do you think Samsung is comparing itself to one particular competitor in the advertisement?" and "do you think Samsung and the competitor(s) both offer the compared attribute, the built-in solar charger?" for the manipulation check of advertising directness and structural alignability, respectively. Participants given direct comparative advertisements reported significantly higher scores (N $=70$, Mean $=6.542)$ than those given indirect comparative advertisements $(\mathrm{N}=82$, Mean $=2.195)$ on the question of "do you think Samsung is comparing itself to one particular competitor in the advertisement?" $F(1,139)=330.853(p<.000)$. In addition, participants given advertisements featuring alignable differences reported significantly higher scores $(\mathrm{N}=80$, Mean $=3.604)$ than those given non-alignable $(\mathrm{N}=72$, Mean $=1.411$ ) on the question of "do you think Samsung and the competitor(s) both offer the compared attribute, the built-in solar charger?," $F(1,139)=59.389(p<.000)$. Therefore, the two manipulations in this study worked as expected.

\section{Results for Moderating Effects}

The results of the ANOVA models showed that the main effect of advertising directness on attitude toward the brand (Cronbach's Alpha $=0.986, F(1,139)=2.607, p=.109$ ) was not significant, which was 
consistent with what was hypothesized. Then, the test for the moderating effect of structural alignability was conducted. In Hypothesis, it was addressed that structural alignability moderated the relationship between advertising directness and attitude toward the brand. Consistent with the hypothesis, the interaction between advertising directness and structural alignability was significant for attitude toward the brand, $F(1,139)=3.952(p=.049)$. Then, a planned contrast analysis for attitude toward the brand was conducted to test for Hypothesis $1 \mathrm{a}$ and $1 \mathrm{~b}$.

Based on the results of the planned contrast, when the comparative advertisement featured nonalignable differences (alignable was coded as 0 ), indirect comparative advertising (direct was coded as 0 ) significantly generated more positive attitude toward the brand (Mean $=5.960)$ than direct comparative advertising (direct was coded as 1 , Mean $=5.300, F(1,139)=6.189, p=.016$ ). Although $\mathrm{H}_{\mathrm{b}}$ was not supported, a significant opposite result was found. In addition, when the comparative advertisement featured alignable differences (alignable was coded as 1), the difference between the effects of direct (Mean $=5.806$ ) and indirect comparative advertising (Mean $=5.790$ ) on attitude toward the brand was not significant $(F(1,139)=.006, p=.940)$. Therefore, $\mathrm{H}_{\mathrm{a}}$ was supported.

\section{Results for Mediating Effects}

In the marketing literature of comparative advertising, one of the factors that have been found to be effective in affecting the consumer's perception is message informativeness. When the messages are perceived by the consumers as informative or valuable, it is much easier for them to process and retain the information (Moldovan et al. 2019). In addition, the ease to understand the messages helps reduce the counter-arguments and increase the likelihood of liking and enjoying the ad in general (Moldovan et al. 2019). In the past, the concept of informativeness has been investigated mostly as the moderators or dependent variables. However, we believe it can also potentially be the mediator that directly affects the relationship between the directness of the ad and the consumer's attitude.

To test the mediation effect of message informativeness on attitude, we closely followed the approach outlined by Preacher and Hayes (2008) and further illustrated by Zhao, Lynch, and Chen (2010). The findings (based on 1000 bootstrap samples) revealed a significant indirect effect for message informativeness from the bootstrap analysis $(0.34)$, with a $95 \%$ confidence interval that excluded zero $(0.1038-0.6837)$. The total effect was also significant $(p<.05)$. Furthermore, the direct effect $(0.36)$ of message informativeness on attitude was significant $(p<.05)$. The product term of direct and indirect effects for message informativeness was positive $(0.36 * 0.34=0.12)$. This pattern of results indicates an indirectonly mediation (Zhao et al. 2010).

\section{CONCLUSIONS AND DISCUSSIONS}

A conceptual framework was developed to address the research gap on direct versus indirect comparative advertising and also further investigated the effects of one potential moderator and one mediator that could help explain the mixed results found from previous research. These studies described in the previous paragraphs provided invaluable insights for understanding the effectiveness of direct versus indirect comparative advertising, particularly with respect to different formats of comparative advertisements with respect to attributes compared in the ad. As expected, in the study, it was hypothesized that there would be no difference in attitude towards the brand when the comparative advertisement features alignable differences. The findings supported this expectation. Since most comparative advertising research used alignable differences (Griffin and Broniarczyk 2010), this finding was consistent with the inconclusive results for the effectiveness of direct versus indirect comparative advertising.

On the other hand, a significant opposite result was found and showed that indirect comparative advertisements indeed generated more positive attitude towards the brand when the comparative advertisement features nonalignable differences. It can be speculated here that it is better for those firms which want to compare themselves with more than one competitor to develop their own "specialized attributes" rather than focus on the attributes that have been well provided and served by many other companies. This surprising finding was consistent with what Chang and Kukar-Kinney (2007) found. They 
found that the unique or special attribute from a pioneer product received great recalls from consumers and generated high accessibility in consumers' minds.

In addition, the results of the mediation analysis have proven that consumers perceive the messages from direct comparisons are more informative and worthy and then, in turn, improve their attitudes toward the advertised brand. These findings are not surprising and are actually consistent with most of the previous research on direct comparisons. This indirect-only mediating effect provides another explanation for the inconclusive findings of the relationship between advertising directness and consumer attitude. To our best knowledge, this is the first research that specifically focused on the mediating effect of message informativeness on the effectiveness of comparative advertising.

This paper provides several managerial implications and applications. First, the results provide important recommendations to marketing managers that they should make sure that its indirect comparative advertisement features nonalignable differences to claim that they have some "special attributes" that their competitors lack of (Chang 2007). When nonalignable differences are used in the advertising messages, they should claim it is better than others in general instead of naming any specific competitors. By doing this, the firm is further providing evidence that they are indeed the best because no other firm offers the special and unique attribute stated in their advertisement

Although this study provides useful and meaningful insights and managerial implications, there are some limitations. First, this research doesn't consider different levels of "directness" of comparative advertising. In reality, different comparison strategies have been used by companies. For example, some companies only show competitors' logos or brand names in their direct comparative advertisements without naming them in the messages. Some companies included competitors' slogans in their messages to imply who they are referring to (E-surance, an Allstate company, mentions " 15 minutes can save you 15\% of car insurance" in the messages to imply they are comparing to Geico). In both examples, consumers can potentially know the one particular competitor to whom the advertiser compares. Additionally, it also cannot be assumed that consumers perceive "the leading brand" and "other brands" identically. This research only uses "other brands" and "everyone else" in the manipulations of indirect comparative advertisements.

Besides that, generalizability is a concern for both studies. Although different product categories have been used in this research, for each individual moderator, only one study with one particular product has been done. The conclusions of each study is based on findings from a research setting with that particular product. No additional studies are done to try to generalize the findings. Besides that, both studies use products which are generally considered as utilitarian products (cell phone services and tablet computers). Therefore, no hedonic products or attributes are considered in this research.

\section{REFERENCES}

Barry, T.E. (1993, March/April). Comparative Advertising: What Have We Learned in Two Decades? Journal of Advertising Research, pp. 19-29.

Beard, F., \& Nye, C. (2010). Caught In The Middle: A History Of The Media Industry's Self-Regulation Of Comparative Advertising. American Academy of Advertising Conference Proceedings, pp. 5253.

Chang, A.C-C., \& Kukar-Kinney, M. (2007). The impact of a pioneer brand on competition among later entrants. Journal of Customer Behaviour, 6(2), 195-210.

Chang, C. (2007). The Relative Effectiveness of Comparative and Noncomparative Advertising: Evidence for Gender Differences in Information-Processing Strategies. Journal of Advertising, 36(1), 26-35

Donthu, N. (1992). Comparative Advertising Intensity. Journal of Advertising Research, 32(6), 53-58.

Gentner, D., \& Markman, A.B. (1994). Structural Alignment in Comparison: No Difference Without Similarity. Psychological Science (Wiley-Blackwell), 5(3), 152-58.

Grewal, D., Kavanoor, S., Fern, E.F., Costley, C., \& Barnes, J. (1997). Comparative versus noncomparative advertising: A meta-analysis. Journal of Marketing, 61(4), 1-15. 
Griffin, J.G., \& Broniarczyk, S.M. (2010). The Slippery Slope: The Impact of Feature Alignability on Search and Satisfaction. Journal of Marketing Research, 47(2), 323-34.

Hsu, T. (2018). The Effects of Advertising Valence on Comparative Advertising: The Roles of Counterarguments. Journal of Marketing Development and Competitiveness, 12(1), 96-104.

Jain, S.P., Buchanan, B., \& Maheswaran, D. (2000). Comparative Versus Noncomparative Advertising: The Moderating Impact of Prepurchase Attribute Verifiability. Journal of Consumer Psychology, 9(4), 201-11.

Markman, A.B., \& Gentner, D. (1997), The Effects of Alignability on Memory. Psychological Science (Wiley-Blackwell), 8(5), 363-67.

Miniard, P.W., Barone, M.J., Rose, R.L., \& Manning, K.C. (2006). A Future Assessment of Indirect Comparative Advertising Claims of Superiority Over All Competitors. Journal of Advertising, 35(4), 53-64.

Moldovan, S., Steinhart, Y., \& Lehmann, D.R. (2019). Propagators, Creativity, and Informativeness: What Helps Ads Go Viral. Journal of Interactive Marketing, 47(2019), 102-114.

Na, W., Son, Y., \& Marshall, R. (2006). The Structural Effect of Indirect Comparative Advertisements on Consumer Attitude, When Moderated by Message Type and Number of Claims. In Advances in Consumer Research - Asia-Pacific Conference Proceedings (Vol. 7). Association for Consumer Research.

Pechmann, C., \& Esteban, G. (1993). Persuasion Processes Associated With Direct Comparative and Noncomparative Advertising and Implications for Advertising Effectiveness. Journal of Consumer Psychology (Lawrence Erlbaum Associates), 2(4), 403.

Pechmann, C., \& Ratneshwar, S. (1991). The Use of Comparative Advertising for Brand Positioning: Association versus Differentiation. Journal of Consumer Research, 18(2), 145-160.

Pechmann, C., \& Stewart, D.W. (1990). The Effects of Comparative Advertising on Attention, Memory, and Purchase Intentions. Journal of Consumer Research, 17, 180-191.

Pechmann, C., \& Stewart, D.W. (1991). How Direct Comparative Ads and Market Share Affect Brand Choice. Journal of Advertising Research, pp. 47-55.

Pride, W.M., Lamb, C.W., \& Pletcher, B.A. (1979). The Informativeness of Comparative Advertisements: An Empirical Investigation. Journal of Advertising, 8(2), 29-48.

Priester, J.R., Godek, J., Nayakankuppum, D.J., \& Park, K. (2004). Brand Congruity and Comparative Advertising: When and Why Comparative Advertisements Lead to Greater Elaboration. Journal of Consumer Psychology (Lawrence Erlbaum Associates), 14(1/2), 115-23.

Schwaiger, M., Rennhak, C., Taylor, C.R., \& Cannon, H.M. (2007). Can Comparative Advertising Be Effective in Germany? A Tale of Two Campaigns. Journal of Advertising Research, 47(1), 2-13.

Shao, A.T., Bao, Y., \& Gray, E. (2004). Comparative Advertising Effectiveness: A Cross-Cultural Study. Journal of Current Issues \& Research in Advertising (CTC Press), 26(2), 67-80.

Snyder, R. (1992). Comparative Advertising and Brand Evaluation: Toward Developing a Categorization Approach. Journal of Consumer Psychology (Lawrence Erlbaum Associates), 1(1), 15.

Wilkie, W.L., \& Farris, P.W. (1975). Comparison Advertising: Problems and Potential. Journal of Marketing, 39(4), 7-15.

Yang, X., Jain, S., Lindsey, C., \& Kardes, F. (2007). Perceived Variability, Category Size, and the Relative Effectiveness of "Leading Brand" Versus "Best in Class" Comparative Advertising Claims. Advances in Consumer Research, 34, 209-09.

Zhang, L., Moore, M., \& Moore, R. (2011). The Effect of Self-Construal on the Effectiveness of Comparative Advertising. Marketing Management Journal, 21(1), 195-206.

Zhang, S., \& Fitzsimons, G.J. (1999). Choice-Process Satisfaction: The Influence of Attribute Alignability and Option Limitation. Organizational Behavior \& Human Decision Processes, 77(3), 192-214.

Zhang, S., \& Markman, A.B. (2001). Processing Product Unique Features: Alignability and Involvement in Preference Construction. Journal of Consumer Psychology, 11(1), 13-27. 
Zhang, S., Kardes, F.R., \& Cronley, M.L. (2002). Comparative Advertising: Effects of Structural Alignability on Target Brand Evaluations. Journal of Consumer Psychology, 12(4), 303-11.

Zhao, X., Lynch, J.G., Jr., \& Qimei Chen, Q. (2010). Reconsidering Baron and Kenny: Myths and Truths about Mediation Analysis. Journal of Consumer Research, 37(2), 197-206.

\section{APPENDIX}

FIGURE 1

ADS USED IN THE STUDY

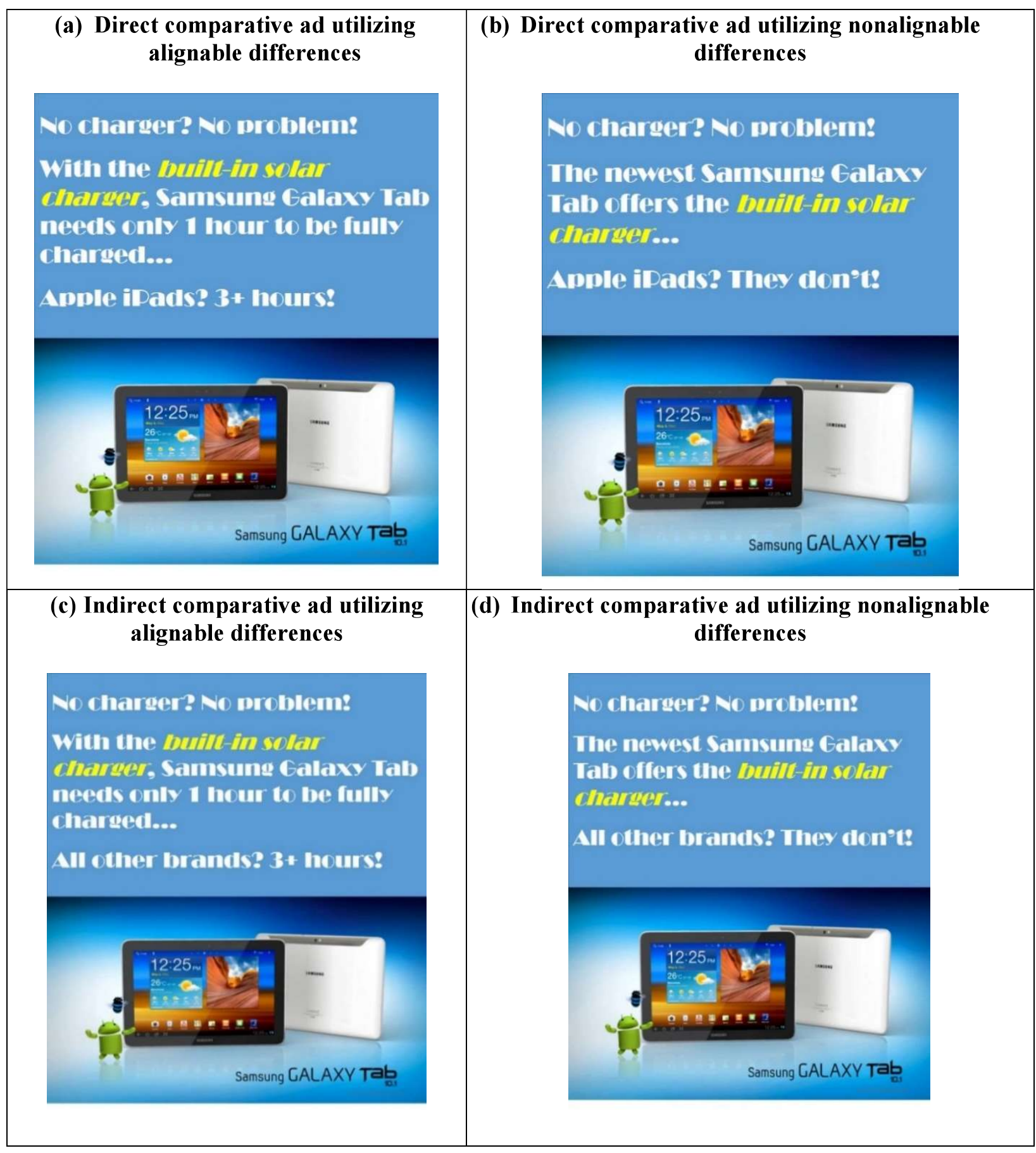


TABLE 1

ANOVA RESULTS OF THE STUDY

Dependent Variable: Attitude toward the Brand

\begin{tabular}{|c|c|c|c|c|c|}
\hline Source & $\begin{array}{c}\text { Type III Sum of } \\
\text { Squares }\end{array}$ & $\begin{array}{c}\text { Degrees of } \\
\text { Freedom }\end{array}$ & $\begin{array}{c}\text { Mean } \\
\text { Square }\end{array}$ & F & Sig. \\
\hline Intercept & 1.328 & 1 & 1.328 & 1.526 & .219 \\
Involvement & .063 & 1 & .063 & .072 & .789 \\
Pre-Attitude & 42.319 & 1 & 42.319 & 48.640 & .000 \\
Familiarity & .636 & 1 & .636 & .731 & .394 \\
Importance & 25.018 & 1 & 25.018 & 28.755 & .000 \\
NFC & .030 & 1 & .030 & .035 & .852 \\
Age & .349 & 1 & .349 & .402 & .527 \\
Gender & 2.979 & 1 & 2.979 & 3.424 & .066 \\
Race & .061 & 1 & .061 & .070 & .792 \\
Time Spent & .562 & 1 & .562 & .646 & .423 \\
Direct & 2.269 & 1 & 2.269 & 2.607 & .109 \\
Alignable & 2.428 & 1 & 2.428 & 2.790 & .097 \\
Direct* Alignable & 3.438 & 1 & 3.438 & 3.952 & .049 \\
Error & 120.935 & 139 & .870 & & \\
Total & 5238.360 & 152 & & & \\
Corrected Total & 261.044 & 151 & & & \\
\hline
\end{tabular}

a. R Squared $=.537$ (Adjusted R Squared $=.497$ )

FIGURE 2

THE MODERATING EFFECT OF STRUCTURAL ALIGNABILITY ON ATTITUDE TOWARD THE BRAND

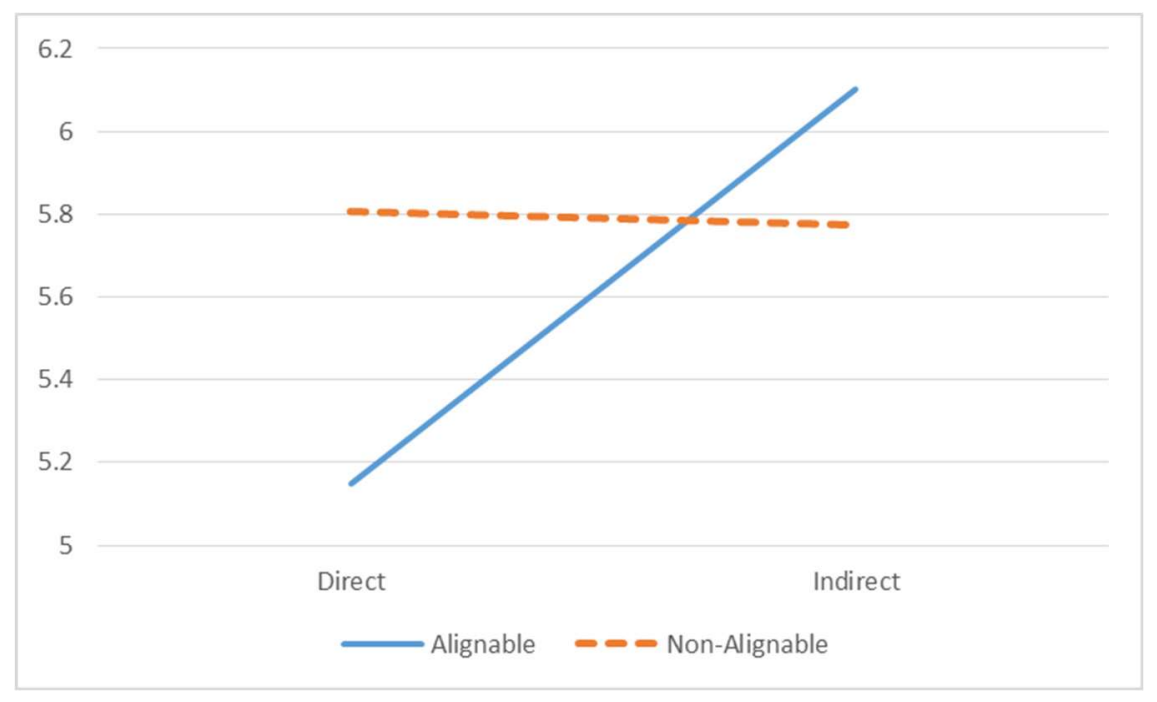

